\title{
Modification of Human Pericardium by Chemical Crosslinking
}

\author{
Elena FILOVÁ ${ }^{\mathbf{1}}$, Lubica STAŇKOVÁ ${ }^{\mathbf{1}}$, Adam ECKHARDT ${ }^{\mathbf{1}}$, Jana SVOBODOVÁ ${ }^{\mathbf{1}}$, Jana \\ MUSÍLKOVÁ ${ }^{1}$, Jan PALA ${ }^{2,3}$, Daniel HADRABA ${ }^{1,4}$, Eduard BRYNDA ${ }^{5}$, Miroslav \\ KOŇǍ̌́́K ${ }^{6}$, Jan PIRK ${ }^{6}$, Lucie BAČÁKOVÁ ${ }^{1}$
}

${ }^{1}$ Laboratory of Biomaterials and Tissue Engineering, Institute of Physiology of the Czech Academy of Sciences, Prague, Czech Republic, ${ }^{2}$ Third Medical Faculty, Charles University in Prague, Institute of Pathophysiology, Prague, Czech Republic, ${ }^{3}$ National Institute of Mental Health, Klecany, Czech Republic, ${ }^{4}$ Faculty of Physical Education and Sport, Charles University, Prague, Czech Republic, ${ }^{5}$ Institute of Macromolecular Chemistry of the Czech Academy of Sciences, Prague, Czech Republic, ${ }^{6}$ Institute for Clinical and Experimental Medicine, Prague, Czech Republic

Received October 3, 2019

Accepted December 11, 2019

Epub Ahead of Print December 19, 2019

\begin{abstract}
Summary
Autologous and allogenic human pericardia used as biomaterials for cardiovascular surgery are traditionally crosslinked with glutaraldehyde. In this work, we have evaluated the resistivity to collagenase digestion and the cytotoxicity of human pericardium crosslinked with various concentrations of glutaraldehyde in comparison with pericardium crosslinked by genipin, nordihydroguaiaretic acid, tannic acid, and in comparison with unmodified pericardium. Crosslinking retained the wavy-like morphology of native pericardium visualized by second harmonic generation microscopy. The collagenase digestion products were analyzed using SDS-PAGE, capillary electrophoresis, and a hydroxyproline assay. Glutaraldehyde and genipin crosslinking protected the native pericardium efficiently against digestion with collagenase III. Only low protection was provided by the other crosslinking agents. The cytotoxicity of crosslinked pericardium was evaluated using xCELLigence by monitoring the viability of porcine valve interstitial cells cultured in eluates from crosslinked pericardium. The highest cell index, reflecting both the number and the shape of the monitored cells was observed in eluates from genipin. Crosslinking pericardium grafts with genipin therefore seems to be a promising alternative procedure to the traditional crosslinking with glutaraldehyde, because it provides similarly high protection against degradation with collagenase, without cytotoxic effects.
\end{abstract}

\section{Key words}

Human pericardium - Valve interstitial cells - Chemical crosslinking • Genipin • Glutaraldehyde

\section{Corresponding author}

E. Filova, Laboratory of Biomaterials and Tissue Engineering, Institute of Physiology of the Czech Academy of Sciences, Videnska 1083, 14220 Prague 4, Czech Republic. Fax: +420 244 472 269. E-mail: elena.filova@fgu.cas.cz

\section{Introduction}

Both autologous and allogenic human pericardium are used as biomaterials for applications in tissue regeneration (Lam and $\mathrm{Wu}$ 2012). Fresh autologous pericardium has desirable characteristics for cardiovascular implantation. It has been used for patches, baffles, valve substitutes and conduits in the field of surgical repairs for congenital and acquired cardiovascular defects. Autologous pericardium is nonimmunogenic and free from donor-derived pathogens. In order to facilitate the handling of pericardium in surgery, its toughness and shape stability have often been improved by treatment with glutaraldehyde (GA) (Jonas 2014, Remi et al. 2011, Kawase et al. 2013). However, there is only limited availability of autologous human pericardium, due to the risk of inflammatory complications after pericardiotomy.

Allogenic human pericardium has to be processed prior to implantation in order to reduce the immunological response of the recipient's organism (Badylak and Gilbert 2008). In a traditional approach, 
commercially-available cryopreserved human cardiac allografts (e.g. CryoLife) (Lee et al. 2017) are treated with GA, as a result of which potential adverse effects of foreign cells, cell debris and possible donor-derived pathogens are disabled. However, GA-treated tissues are prone to calcification after long-term implantation (Lam and $\mathrm{Wu}$ 2012, Remi et al. 2011, Lee et al. 2017). Moreover, GA-fixed tissues caused an increase in circulating cytotoxic $\mathrm{T}$ cells, helper $\mathrm{T}$ cells and anti-HLA antibodies (Vinci et al. 2013, Welters et al. 2001). The inflammatory process induced by GA cytotoxicity is probably involved in the calcification mechanism (Remi et al. 2011).

Compared to GA-fixed bovine pericardium grafts, genipin-fixed grafts induce significantly weaker inflammatory reactions, and their regeneration is far faster (Chang et al. 2002). Natural compounds, such as nordihydroguaiaretic acid (NDGA), tannic acid (TA), and procyanidins, or chemical compounds such as epoxides, carbodiimide, and others, have been used for crosslinking cardiovascular scaffolds derived from extracellular matrix (Ma et al. 2014).

In this study, the treatment of native human pericardium with genipin, NDGA and TA was compared with GA-fixation in relation to the resistivity of pericardium against digestion with collagenase III. The potential cytotoxicity of the pericardium was estimated by the growth of valve interstitial cells (VICs) in eluates from this pericardium, monitored in real-time in the sensoric xCELLigence system.

\section{Methods}

\section{Chemical and biochemical substances}

Glutaraldehyde (Polysciences, Inc., Cat. No. 00216, Warrington, PA, USA), genipin (Sigma, Cat. No. G4796, St. Louis, MO, USA), tannic acid (Sigma, Cat. No. 96311-250G-F, St. Louis, MO, USA), and nordihydroguaiaretic acid (Sigma, Cat. No. 74540, St. Louis, MO, USA) were used for pericardium crosslinking. Collagenase III solution (Cat. No. LS004208, $149 \mathrm{U} / \mathrm{ml}$ ) was purchased from Worthington Biochemical Corp (Lakewood, NJ, USA). The reducing sample buffer (with sodium dodecyl sulfate SDS, 1.6\%, and mercaptoethanol, $4 \%$ used in SDS-PAGE electrophoresis, trypsin from bovine pancreas (TPCK treated) used in capillary electrophoresis, and phosphatebuffered saline, pH 7.4, (PBS) were from Sigma Aldrich (St. Louis, MO, USA). The P4417-100TAB Dulbecco- modified Eagle Minimum Essential Medium (DMEM; Gibco ${ }^{\circledR}$; Cat. No. 52100-021) was purchased from Life Technologies Czech Republic s.r.o., and the Gentamicin was purchased from LEK, Ljubljana. The fetal bovine serum (FBS) was purchased from Sebak $\mathrm{GmbH}$, Aidenbach, Germany.

\section{Pericardium harvesting}

Human fibrous pericardium was harvested from the anterior part of the heart of 6 patients during open heart surgery. The pericardium samples were rectangular and their area was in the range from 18 to $32 \mathrm{~cm}^{2}$. All patients signed an informed consent form prior to enrolment in the study. The harvested pericardium was stored in DMEM cell cultivation medium supplemented with gentamicin $(40 \mu \mathrm{g} / \mathrm{ml})$ and $10 \%$ FBS while it was being washed with PBS. Samples for the experiments were cut off it and were weighed in wet state. The study was approved by the Ethics Committee of the Institute for Clinical and Experimental Medicine and Thomayer Hospital in Prague, approvals Nos. G09-12-30, C.j. 2401/09, and G14-08-63, approved on August 13 ${ }^{\text {th }}, 2014$.

\section{Crosslinked pericardium (cP)}

Pieces of native pericardium (nP) were washed with PBS, and were crosslinked with glutaraldehyde, genipin, tannic acid or NDGA for $48 \mathrm{~h}$ at room temperature (Table 1). Stock $8 \mathrm{wt} \%$ glutaraldehyde solution was diluted with PBS. Genipin was dissolved in dimethyl sulfoxide (DMSO) into a $2.5 \mathrm{wt} \%$ solution and was then diluted with PBS. Tannic acid was dissolved in

Table 1. The concentrations of glutaraldehyde, genipin, NDGA and tannic acid.

\begin{tabular}{|c|c|c|c|}
\hline \multicolumn{2}{|c|}{ Glutaraldehyde } & \multicolumn{2}{|c|}{ Genipin } \\
\hline wt $\%$ & $\mathbf{M}$ & wt\% & $\mathbf{M}$ \\
\hline 0.004 & 0.0004 & 0.05 & 0.0022 \\
\hline 0.0124 & 0.00124 & 0.1 & 0.0044 \\
\hline 0.0256 & 0.00256 & 0.25 & 0.011 \\
\hline 0.16 & 0.016 & 0.5 & 0.022 \\
\hline 0.4 & 0.04 & \multicolumn{2}{|c|}{ Tannic acid } \\
\hline 4.0 & 0.4 & wt\% & $\mathbf{M}$ \\
\hline \multicolumn{2}{|c|}{$N D G A$} & 0.05 & 0.00029 \\
\hline $\mathrm{mg} / \mathrm{ml}$ & M & 0.1 & 0.00059 \\
\hline 0.5 & 0.0017 & 0.25 & 0.0015 \\
\hline 1 & 0.0033 & 0.5 & 0.0029 \\
\hline 2 & 0.0066 & 1 & 0.0059 \\
\hline 4 & 0.013 & 2 & 0.012 \\
\hline
\end{tabular}


PBS to $2 \mathrm{wt} \%$ and was then diluted with PBS. NDGA was dissolved in DMSO $(20 \mathrm{mg} / \mathrm{ml})$ and was then diluted with PBS.

\section{Second harmonic generation (SHG) imaging}

SHG images of native and crosslinked pericardium were acquired by the laser scanning confocal system (Leica DM IRE2 inverted microscope, Leica TCS SP2 AOBS confocal microscope and Leica TCS SP8 AOBS WLL MP confocal microscope, Germany, confocal scan head). The second harmonic signal was induced by tuning the Chameleon Ultra II laser (Coherent, Santa Clara, CA, USA) to $860 \mathrm{~nm}$ linear polarized light. The incident beam reached the sample through the objective (Leica HC PL APO CS 20.0x/0.70 IMM/CORR UV CS - corr. ring set for W), and the backscattered SHG signal was expected at half the excitation wavelength, i.e. $430 \mathrm{~nm}$, at the non-descanned PMT detector (band pass filter HQ430/20 M-2P, Chroma, Irvine, CA, USA). The nature of the SHG signal was confirmed by changing the excitation wavelength to $800 \mathrm{~nm}$. The z-stack images were acquired with $10 \mu \mathrm{m}$-depth thickness for voxel size 0.18:0.18:2.50 $\mu \mathrm{m}$ [X:Y:Z].

\section{Collagenase treatment}

Wet samples of native or crosslinked pericardium were washed three times in PBS and were weighed. A sample of about $100 \mathrm{mg}$ was incubated at $37^{\circ} \mathrm{C}$ in a collagenase III solution corresponding in volume (in $\mu$ l) to 10 times the weight of the sample (in $\mathrm{mg})$.

One-dimensional sodium dodecyl sulfate-polyacrylamide gel electrophoresis (SDS-PAGE)

A part of the native or crosslinked pericardium $(20 \mu \mathrm{g})$ obtained after incubation with collagenase III for $4 \mathrm{~h}$ at $37^{\circ} \mathrm{C}$ was lyophilized and was extracted by incubation with $120 \mu \mathrm{l}$ of a reducing sample buffer (0.05 M tris(hydroxymethyl)aminomethan buffer $\mathrm{pH} 6.8$, SDS $1.6 \% \mathrm{w} / \mathrm{w}$, and mercaptoethanol $4 \% \mathrm{v} / \mathrm{v}$, Sigma) for $10 \mathrm{~min}$ at $105^{\circ} \mathrm{C}$ with shaking. The extract solution was analysed by SDS-PAGE using homogeneous $10 \%$ polyacrylamide resolving gel according to the methods described by Laemmli (Laemmli 1970). Finally, $5 \mu$ l of Precision Plus Protein ${ }^{\mathrm{TM}}$ Standards (molecular weight range 10-250 kDa, Bio-Rad, Prague, Czech Republic) was added at the top end of the gel. The gels were released into the Mini-Protean ${ }^{\circledR}$ Tetra cell system (BioRad, Prague, Czech Republic) at $200 \mathrm{~V}$ until the bromophenol blue reached the end of the gel (ca. $45 \mathrm{~min}$ ). The gels were then stained with Bio-Safe ${ }^{\mathrm{TM}}$ Coomassie Blue G250 Stain (Bio-Rad, Prague, Czech Republic). After staining, the gels were washed with water, were scanned with a GS-800 Calibrated Densitometer, and were processed with image analysis software (Quantity One $^{\circledR}$, Bio-Rad, Prague, Czech Republic).

\section{Capillary electrophoresis}

Samples of pericardium were treated with collagenase III for $4 \mathrm{~h}$, and were dried, were digested for $5 \mathrm{~h}$ using trypsin $\left(0.2 \mathrm{mg} / \mathrm{ml}, 0.1 \mathrm{M} \mathrm{NH}_{4} \mathrm{HCO}_{3}, \mathrm{pH} 7.8\right)$, were boiled for $15 \mathrm{~min}$ at $105^{\circ} \mathrm{C}$, were dried and were again immersed into trypsin of the same concentration for $5 \mathrm{~h}$. The trypsin-to-dry-sample weight ratio was kept at 1:100. The twice digested samples were dried, dissolved in the electrophoretic buffer, were sonicated for $15 \mathrm{~min}$ and were filtered using a $0.20 \mu \mathrm{m}$ filter (Millex-LG, Japan). The final concentration of each sample was $10 \mathrm{mg} / \mathrm{ml}$ (calculated to the dry weight of the tissue).

Electrophoretic separations were performed using Beckmann P/ACE System 5500 apparatus with UV detection set to $214 \mathrm{~nm}$. For all separations, we used a fused silica capillary $37 \mathrm{~cm}$ in total length $(30 \mathrm{~cm}$ to the detector) and $75 \mu \mathrm{m}$ in inner diameter (Composite Metal Service LTD, The Chase, Hallow, Worcestershire, UK). All separations were run in $0.1 \mathrm{M}$ phosphate buffer, $\mathrm{pH}$ 2.5. For each electrophoretic experiment, $20 \mu \mathrm{l}$ of sample solution was pipetted; the duration of injection was set to $3 \mathrm{~s}$. The separation voltage was set to $10 \mathrm{kV}$ at $20^{\circ} \mathrm{C}$, and the separation time was $80 \mathrm{~min}$. Before each electrophoresis, the capillary was prewashed with water, $1 \mathrm{M} \mathrm{HCl}$, water and running buffer, with 2 min for each step.

\section{Hydroxyproline assay}

The solutions that had arisen after 1, 2, 3, and $4 \mathrm{~h}$ treatment of native pericardium or after 1 and $3 \mathrm{~h}$ treatment of crosslinked pericardium with collagenase III at $37^{\circ} \mathrm{C}$ were tested using the Hydroxyproline assay kit (BioVision, Cat. No. K555-100, Milpitas, CA, USA). Briefly, $100 \mu \mathrm{l}$ of sample solution with $100 \mu \mathrm{l}$ of $\mathrm{HCl}(36 \%)$ was incubated for $3 \mathrm{~h}$ at $120^{\circ} \mathrm{C}$. Ten $\mu \mathrm{l}$ of the solutions in triplicate were pipetted into a 96 -well plate, were dried out, and $100 \mu \mathrm{l}$ of chloramin $\mathrm{T}$ reagent was added and then incubated for $5 \mathrm{~min}$. Finally, $100 \mu \mathrm{l}$ 4-(N,N-dimethylamino)-benzaldehyde (DMAB) reagent was added, was incubated at $60{ }^{\circ} \mathrm{C}$ for $90 \mathrm{~min}$, and was measured at $560 \mathrm{~nm}$ on a VERSAmax tunable microplate reader (Molecular Devices, San Jose, CA, USA). 
A calibration curve was prepared by adding hydroxyproline standard into the wells at a concentration of $0,0.2,0.4,0.6,0.8$, and $1 \mu \mathrm{g}$ per well.

\section{$x$ CELLigence (Cell Index)}

Native and crosslinked pericardium samples were washed with PBS containing $0.2 \mathrm{M}$ glycine and $2.5 \%$ Antibiotic Antimycotic solution (all chemicals from Sigma-Aldrich) for 14 days, replacing the buffer each day. Glycine could deactivate residues of the crosslinking agents capable of producing a covalent reaction with amine groups. Then eluates were prepared by incubating pericardium samples with DMEM supplemented with gentamicin $(40 \mu \mathrm{g} / \mathrm{ml})$ for 3 days; $1 \mathrm{~cm}^{2}$ of the sample was used per $1 \mathrm{ml}$ of the medium. The eluates were supplemented with $10 \%$ FBS and were used for the cultivation of porcine VICs seeded at a density of 3000 cells $/ 200 \mu \mathrm{l}$ on the bottoms of the wells in a microtiter plate (E-Plate 96, Cat. No. 077601, Acea
Biosciences, Inc., CA, USA).

The cell index, reflecting the number and the spreading area of the seeded cells, was determined using the xCELLigence System (Roche Applied Science, Basel, Switzerland) on day 5 after seeding. The cell index of the VICs cultivated in DMEM supplemented with gentamicin and $10 \%$ FBS was used as a control. Passages 3-7 of the VICs isolated and characterized according to Liskova et al. (2017) were used for the experiments.

\section{Results}

\section{SHG imaging}

Figure 1 shows SHG images of multilayered, multidirectionally oriented and overlapping collagen fiber bundles forming a densely woven network in fibrous pericardium. The typical collagen structure of native pericardium (Straka et al. 2018), was preserved after crosslinking with any of the crosslinking agents.
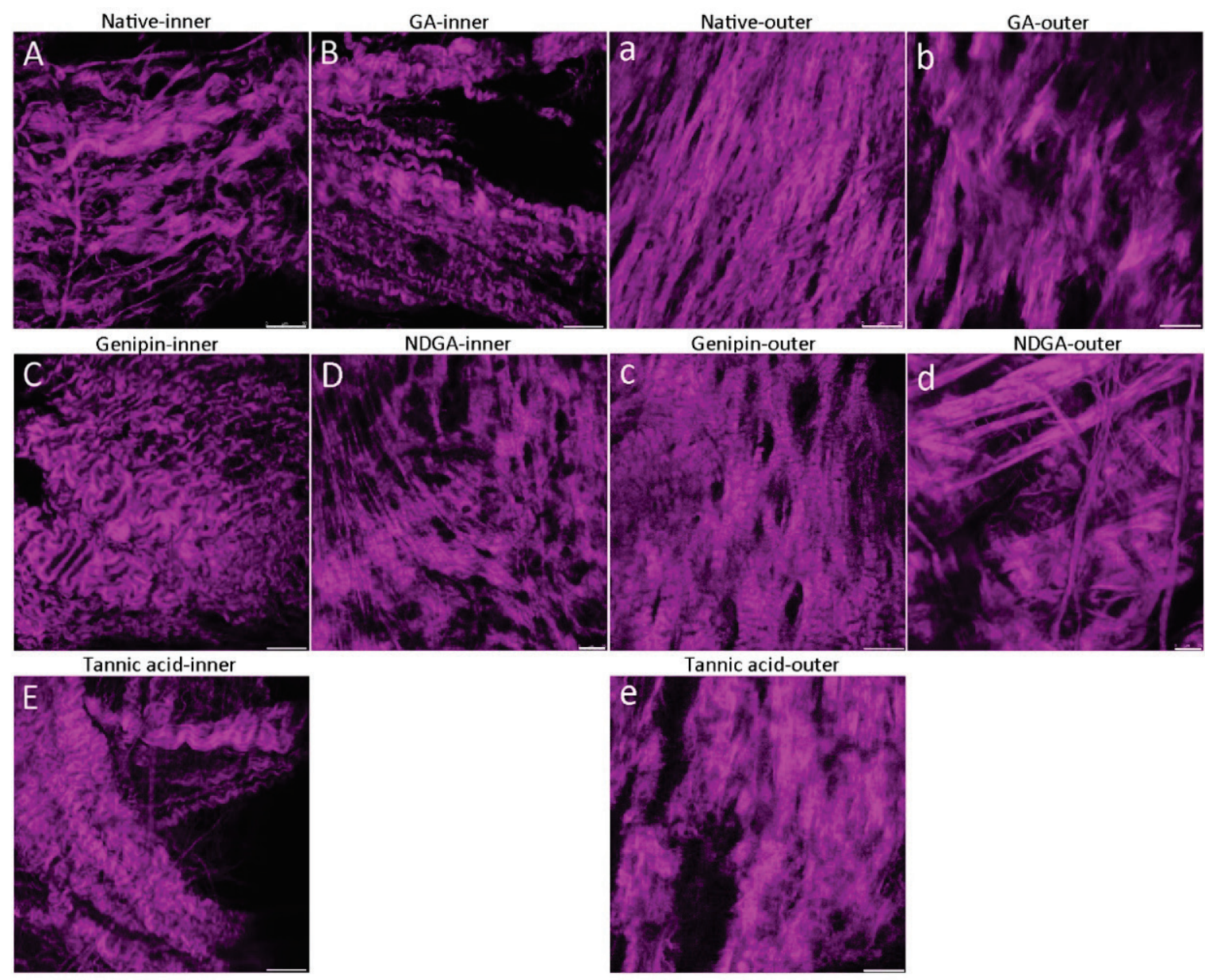

Fig. 1. Second harmonic generation images of fibrillar collagen in the inner side (A-E) (close to the heart) and the outer side (reverse to the heart) (a-e) of human pericardium. Native pericardium $(\mathbf{A}, \mathbf{a})$ was treated with glutaraldehyde $0.40 \mathrm{M}$ (B, b), genipin $0.022 \mathrm{M}(\mathbf{C}, \mathbf{C})$, NDGA $0.013 \mathrm{M}(\mathbf{D}, \mathbf{d})$, and tannic acid $0.012 \mathrm{M}(\mathbf{E}, \mathbf{e})$, Leica SP2 confocal microscope, objective $\times 20$, zoom $\times 2$, scale bar $=50 \mu \mathrm{m}(A-C, E, a-C, e)$, Leica TCS SP8 AOBS WLL MP confocal microscope, scale bar=25 $\mu \mathrm{m}(\mathrm{D}, \mathrm{d})$ in the bottom right corner of the images. 


\section{SDS-PAGE electrophoresis}

The SDS-PAGE electropherograms of extracts from $\mathrm{nP}$ in Figure 2 show typical bands of collagen fragments obtained by collagenase digestion at $37^{\circ} \mathrm{C}$ (Shoulders and Raines 2009). If pericardium was crosslinked with increasing concentrations of GA (Fig. 2a) or genipin (Fig. 2b), the absence of a collagen part alpha 2 band at about $104 \mathrm{kDa}$ was observed in extracts from pericardium crosslinked with GA $0.016 \mathrm{M}$ or genipin $0.0044 \mathrm{M}$. The band of collagen part alpha 1 at about $142 \mathrm{kDa}$ disappeared at concentrations of GA $0.016 \mathrm{M}$ or genipin $0.011 \mathrm{M}$. Collagen chains alpha 1 and alpha 2 were detectable in the extracts from pericardium treated with NDGA (Fig. 2c) at all used concentrations (0.0017-0.013 M). Almost no differences could be distinguished between the SDS images of the extracts obtained from $\mathrm{nP}$ and from pericardium crosslinked with TA (Fig. 2d).
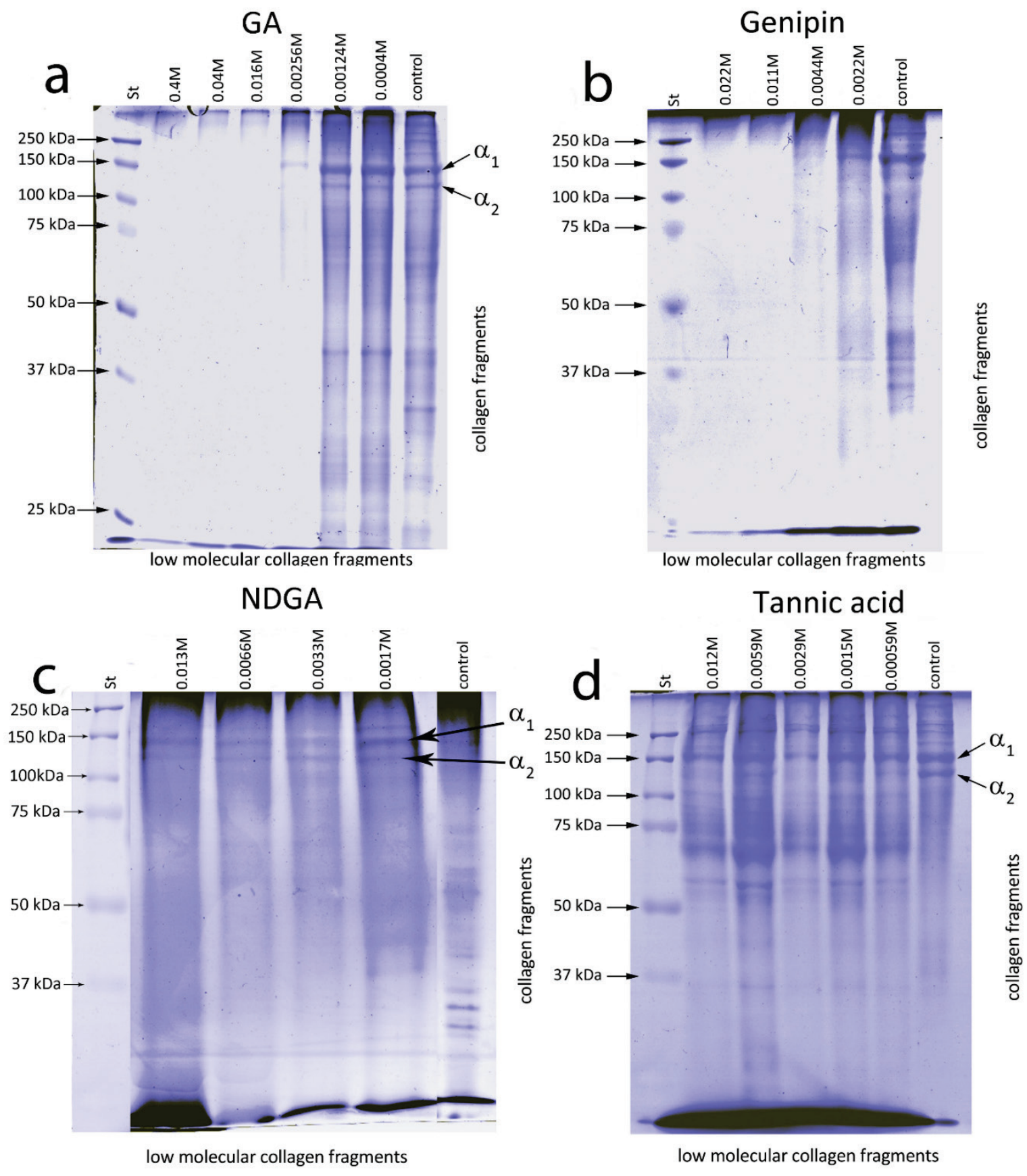

Fig. 2. 1D SDS-PAGE of collagen fragments extracted from human pericardium after incubation with collagenase III for $4 \mathrm{~h}$ at $37^{\circ} \mathrm{C}$. Pericardium was treated with (a) glutaraldehyde (GA) at concentrations of $-0.40,0.04,0.016,0.00256,0.00124,0.0004$, and $0 \mathrm{M}$ (control), (b) genipin at concentrations of $0.022,0.011,0.0044,0.0022 \mathrm{M}$ and $0 \mathrm{M}$ (control), (c) NDGA at the concentrations of 0.013 , $0.0066,0.0033,0.0017 \mathrm{M}$ and $0 \mathrm{M}$ (control), (d) tannic acid at concentrations of 0.012, 0.0059, 0.0029, 0.0015, 0.00059, and $0 \mathrm{M}$. St molecular weight standards. 


\section{Capillary electrophoresis}

Figure 3 shows oligo- and poly-peptide peaks in electropherograms obtained by capillary electrophoresis of solutions prepared by trypsinization of collagenasetreated $\mathrm{nP}$ and crosslinked pericardium. The electropherogram profile of the solution from $\mathrm{nP}$ was not changed when the pericardium was treated with GA at a concentration of $0.0004 \mathrm{M}$ (Fig. 3a, curves a and b). Most peaks disappeared at a GA concentration of $0.0064 \mathrm{M}$ (Fig. 3a, curve c). A further increase in GA concentration had only a minor influence on the electropherograms. The peaks of peptides that appeared before $40 \mathrm{~min}$ were absent in the electropherograms obtained from pericardium crosslinked with genipin at a concentration of $0.0022 \mathrm{M}$ (Fig. 3b, curve b), and all peaks disappeared when higher genipin concentrations were used. The increase in NGDA concentration decreased peak areas without changing profiles of the electropherograms (Fig. 3c). Similarly, the profiles of the electropherograms did not change if pericardium was crosslinked with TA, with the exception of an unexplained increase in the peak appearing at $14 \mathrm{~min}$ in the electropherograms if the TA concentration was increased above $0.00059 \mathrm{M}$ (Fig. 3d, curve c).
GA
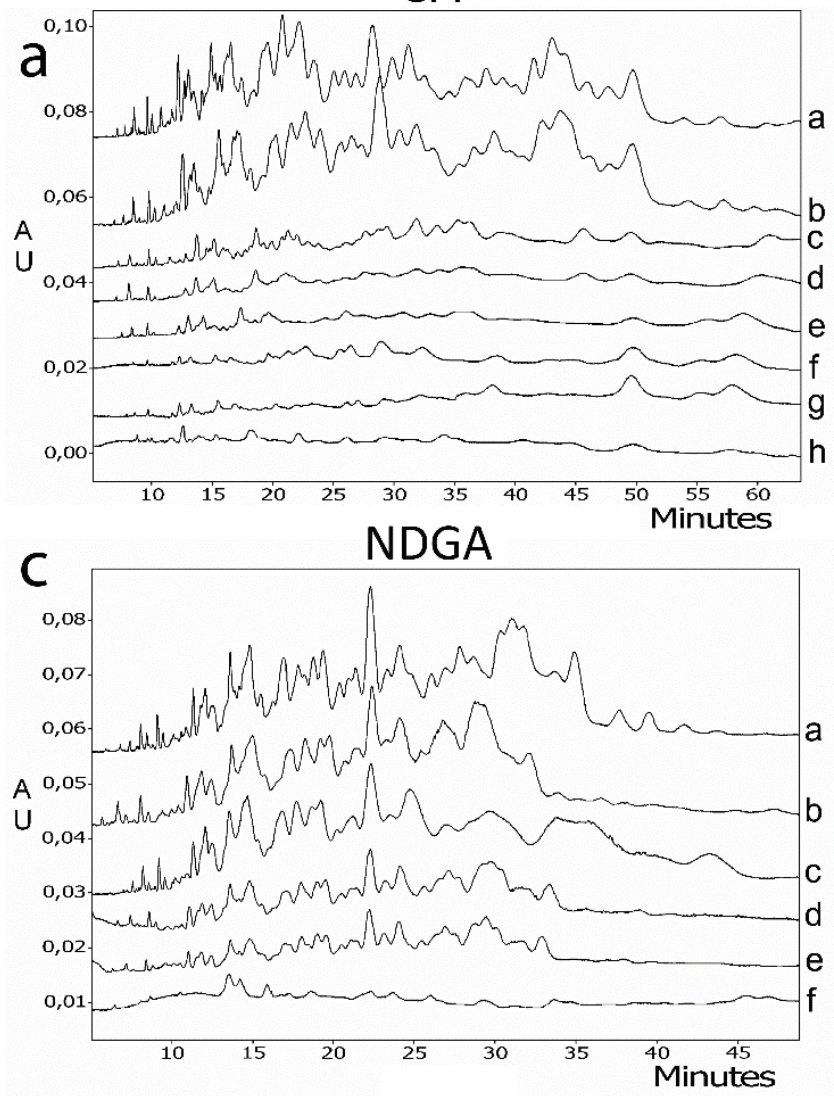

Genipin
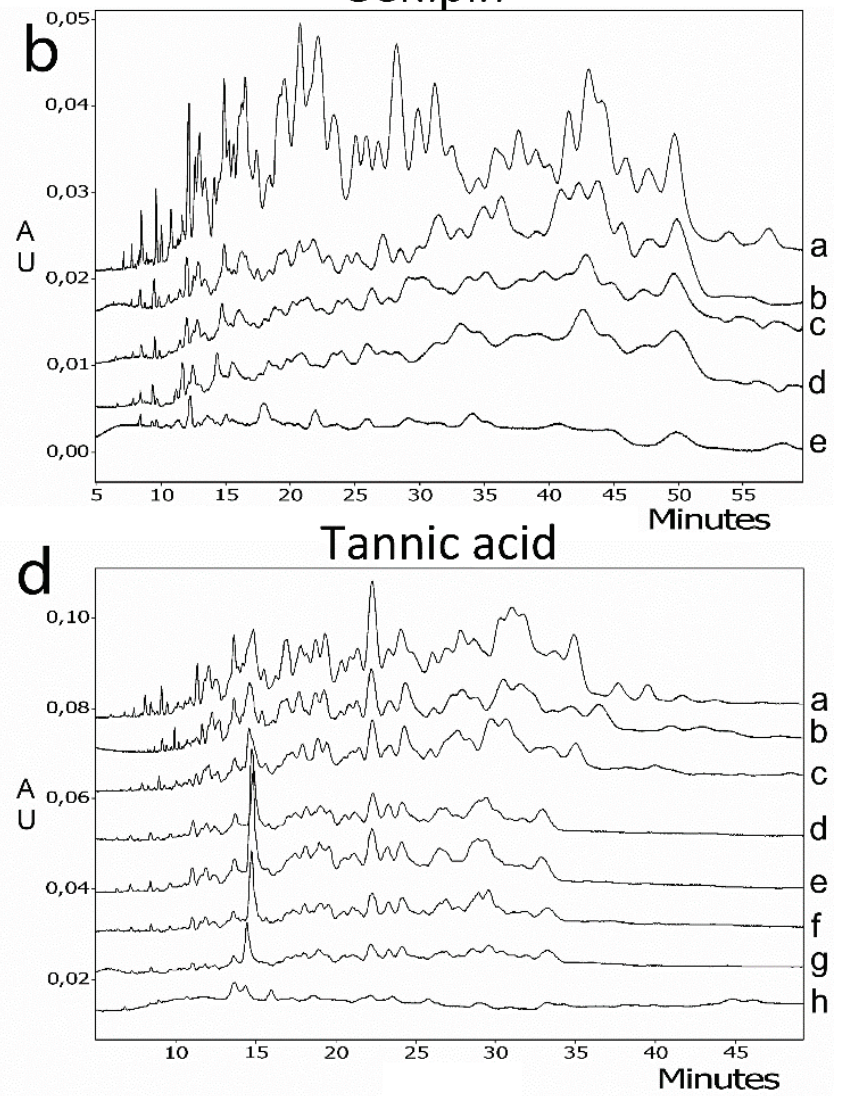

Fig. 3. Capillary electrophoresis of tryptic digests of pericardium (concentration of sample: $10 \mathrm{mg} / \mathrm{ml}$ ) crosslinked with (a) glutaraldehyde (GA) at concentrations of $a=0 \mathrm{M}$ (control); $b=0.0004 \mathrm{M}$ ); $c=0.00124 \mathrm{M} ; \mathrm{d}=0.0064 \mathrm{M} ; \mathrm{e}=0.016 \mathrm{M} ; f=0.04 \mathrm{M} ; \mathrm{g}=0.4 \mathrm{M}$; $\mathrm{h}=$ only trypsin (without sample), (b) genipin at concentrations of $\mathrm{a}=0 \mathrm{M}$ (control); $\mathrm{b}=0.0022 \mathrm{M} ; \mathrm{c}=0.011 \mathrm{M} ; \mathrm{d}=0.022 \mathrm{M} ; \mathrm{e}=0$ only trypsin (without sample), (c) NDGA at concentrations of $a=0$ (control); $b=0.0017 \mathrm{M} ; c=0.0033 \mathrm{M} ; d=0.0066 \mathrm{M}$; $e=0.013 \mathrm{M}$; $f=0$ only trypsin (without sample), and (d) tannic acid at concentrations of $a=0 \mathrm{M}$ (control); $b=0.00029 \mathrm{M} ; \mathrm{c}=0.00059 \mathrm{M} ; \mathrm{d}=0.0015 \mathrm{M}$; $\mathrm{e}=0.0029 \mathrm{M}$; $\mathrm{f}=0.0059 \mathrm{M} ; \mathrm{g}=0.012 \mathrm{M} ; \mathrm{h}=$ only trypsin (without sample). Pericardium was incubated with collagenase for $4 \mathrm{~h}$ at $37^{\circ} \mathrm{C}$ before trypsinization.

\section{Hydroxyproline content}

Figure 4 shows the amounts of hydroxyproline (HP) released from $\mathrm{nP}$ during incubation with collagenase. The mass of the released HP increased linearly with increasing time of incubation, and reached
$0.35 \mu \mathrm{g} / \mathrm{ml}$ for $1 \mathrm{~h}$ of incubation and $0.62 \mu \mathrm{g} / \mathrm{ml}$ for $3 \mathrm{~h}$ of incubation. The mean values of HP (Fig. 5a) released during $1 \mathrm{~h}$ of incubation with collagenase from pericardium crosslinked with GA at any of the concentrations used here (0.4-0.00004 M), and during $3 \mathrm{~h}$ 
from pericardium crosslinked with GA concentrations from 0.4 to $0.004 \mathrm{M}$, were scattered round $0.07 \mu \mathrm{g} / \mathrm{ml}$. The amount of HP released during $3 \mathrm{~h}$ increased significantly to $0.3 \mu \mathrm{g} / \mathrm{ml}$ if the GA concentration was decreased to $0.0004 \mathrm{M}$, and to $0.54 \mu \mathrm{g} / \mathrm{ml}$ if the GA concentration was reduced to $0.00004 \mathrm{M}$. The mean values of HP (Fig. 5b) released during $1 \mathrm{~h}$ of incubation from pericardium crosslinked with genipin at any of the used concentrations (0.022-0.0022 M), and during $3 \mathrm{~h}$ from pericardium crosslinked with genipin at concentrations from 0.022 to $0.0044 \mathrm{M}$, were scattered round $0.1 \mu \mathrm{g} / \mathrm{ml}$. The amount of HP released during $3 \mathrm{~h}$ increased to $0.13 \mu \mathrm{g} / \mathrm{ml}$ if the genipin concentration was $0.0022 \mathrm{M}$. The mean values of HP (Fig. 5c) released from pericardium crosslinked with NGDA during $1 \mathrm{~h}$ of incubation increased gradually from about $0.09 \mu \mathrm{g} / \mathrm{ml}$ to $0.41 \mu \mathrm{g} / \mathrm{ml}$ with decreasing NGDA concentration from 0.013 to $0.0033 \mathrm{M}$. The mean values of HP released during $3 \mathrm{~h}$ increased from about $0.11 \mu \mathrm{g} / \mathrm{ml}$ at NGDA concentrations of $0.013 \mathrm{M}$ and $0.0066 \mathrm{M}$ to $0.57 \mu \mathrm{g} / \mathrm{ml}$ and $0.73 \mu \mathrm{g} / \mathrm{ml}$ at NGDA concentrations of $0.0033 \mathrm{M}$ and $0.0017 \mathrm{M}$, respectively. The mean values of HP (Fig. 5d) released during $1 \mathrm{~h}$ from pericardium crosslinked with tannic acid (TAcP) were scattered close to $0.03 \mu \mathrm{g} / \mathrm{ml}$. The HP released during $3 \mathrm{~h}$ increased linearly from $0.029 \mu \mathrm{g} / \mathrm{ml}$ at a TA concentration of $0.012 \mathrm{M}$ to $0.35 \mu \mathrm{g} / \mathrm{ml}$ at TA $0.00029 \mathrm{M}$.

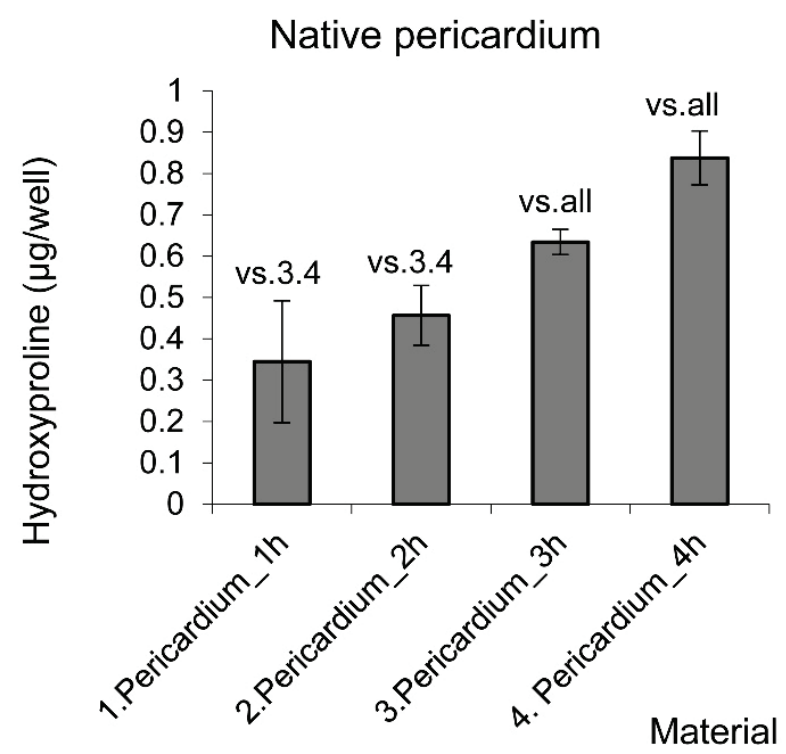

Fig. 4. The amount of hydroxyproline released from native pericardium (from three to six samples of each group) during incubation with collagenase III for $1,2,3$, and $4 \mathrm{~h}$. Data expressed as mean \pm S.D., statistical significance $(p \leq 0.05)$ is labelled above the column in comparison with the sample of the same number. Statistical analysis ANOVA (Student-NewmanKeuls method).
Cell index of porcine valve interstitial cells (VICs) cultivated in eluates from pericardium samples

The cell index of VICs (CI) was measured on day 5 after cell seeding in a medium containing eluates from $\mathrm{nP}$ and crosslinked human pericardium. The CI of VICs cultivated in eluates from $\mathrm{nP}$ did not differ significantly from the $\mathrm{CI}$ in the control pure medium (Fig. 6a) or was significantly lower (Fig. 6b, c). By contrast, nP modification with genipin or NGDA increased the CI (Fig. 6b). Observations indicated that some cytotoxic compounds were released from nP into the eluates, and that crosslinking fixed the compounds inside the pericardium. A statistically significant increase in CI was observed if $\mathrm{nP}$ was fixed with genipin at a concentration of $0.022 \mathrm{M}$; at lower concentrations, the CI was lower. Conversely, CI increased with a decreasing NGDA concentration. Figure $6 \mathrm{a}$ indicates that the mean values of $\mathrm{CI}$ increased if $\mathrm{nP}$ was crosslinked with decreasing GA concentrations from 0.4 to $0.00256 \mathrm{M}$, and that the mean values decreased if the GA concentrations were further decreased. A similar trend is indicated by Figure $6 \mathrm{c}$, in which CI increases with decreasing TA concentration from 0.012 to $0.0015 \mathrm{M}$ (Fig. 6c). While the CI of pericardium fixed with the highest-used concentration of GA was similar to that of $\mathrm{nP}$, the CI was reduced considerably by crosslinking with the highest-used concentration of TA. Some cytotoxicity of GA or TA seemed to reduce the favorable effect of the fixation, which was observed with genipin and NGDA.

\section{Discussion}

As the scaffold of human pericardium tissue is formed mainly from fibres of collagen types I and III, the biological degradation of collagen has a substantial effect on the durability and the function of pericardium-based cardiovascular grafts. The resistance of pericardium to digestion with collagenase at $37^{\circ} \mathrm{C}$ has been studied in this work as an indicator of the susceptibility of pericardium to in vivo degradation.

SDS-PAGE, capillary electrophoresis, and hydroxyproline assay indicated that while an efficient protection against the collagen degradation was reached by the fixation of pericardium with GA or genipin, only minimum protection was obtained by the fixation with NDGA or TA. The results might be understood in the light of various mechanisms of the pericardium fixation on the process of collagen digestion with collagenase. Collagen fibres are formed by tropocollagen molecules 


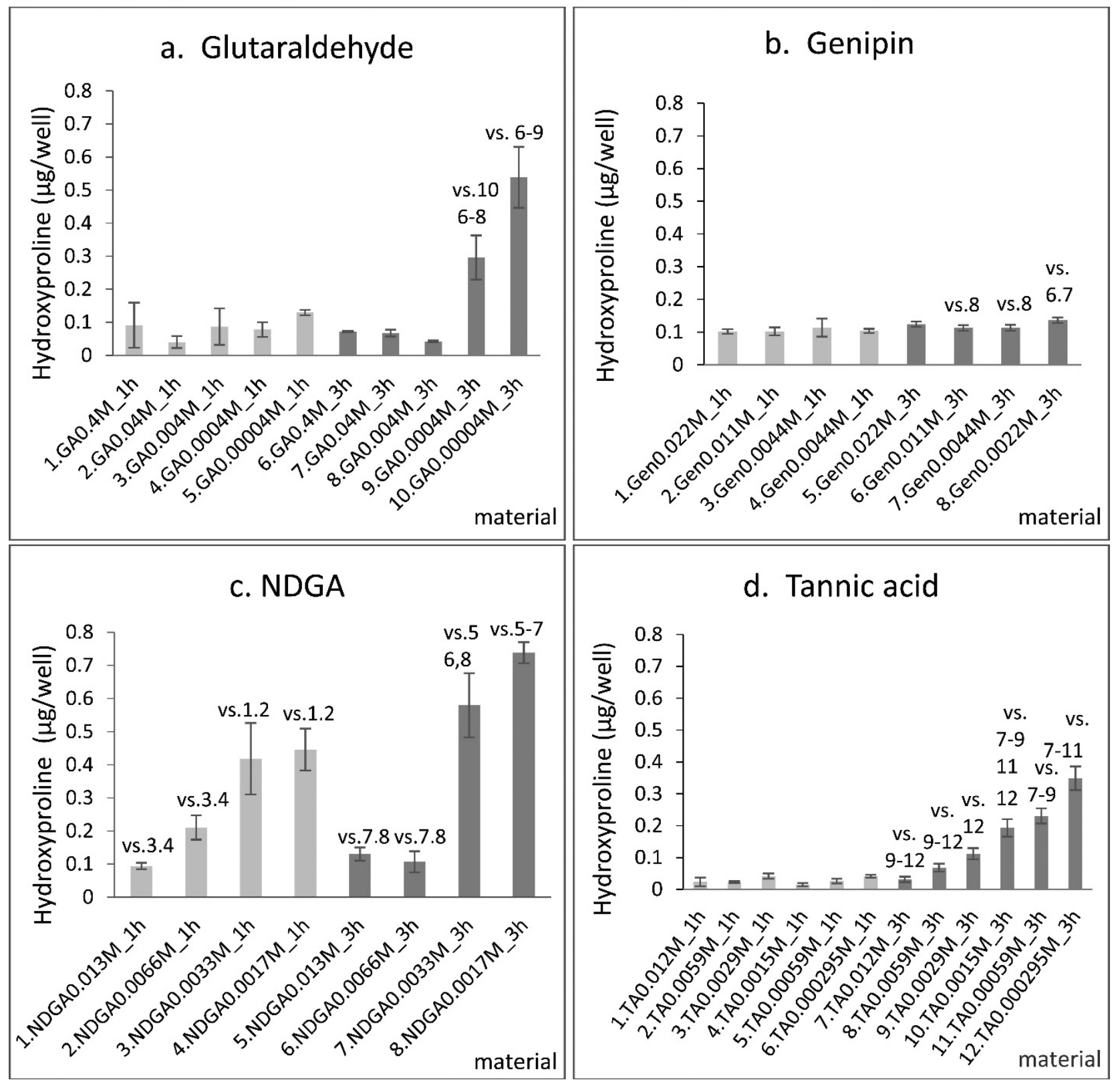

Fig. 5. The amount of hydroxyproline released from crosslinked pericardium during incubation with collagenase III for 1 and $3 \mathrm{~h}$. Pericardium was crosslinked with (a) glutaraldehyde at concentrations of $0.4,0.04,0.004,0.0004$, and $0.00004 \mathrm{M}$, (b) genipin 0.022 , $0.011,0.0044,0.0022 \mathrm{M}$, (c) NDGA 0.013, 0.0066, 0.0033, and 0.0017 M, and (d) tannic acid 0.012, 0.0059, 0.0029, 0.0015, 0.00059, and 0.00029 M. Data are expressed as mean \pm S.D., statistical significance was considered for $p \leq 0.05$ and was labelled above the column in comparison with the sample of the same number, from 3-6 samples of each group, statistical analysis ANOVA, StudentNewman-Keuls method.

made up of three $\alpha$-helix polypeptide chains (Shoulders and Raines 2009, Bunyaratavej and Wang 2001). Collagenase initiates collagen degradation by locally unwinding the triple-helical tropocollagen structure before cleaving $\alpha$ chains at specific sites (Chung et al. 2004).

GA monomers and oligomers crosslink pericardium by the formation of covalent bonds between their aldehyde groups and primary amine groups of lysine or hydroxylysine amino acid residues that are located at various sites of the pericardium structure (mainly in collagen and also in minor proteins) (Mingeault et al. 2004). Like GA, genipin crosslinks proteins by reacting with primary amino groups. By a two-stage reaction, genipin can form dimeric genipin crosslinks within a tropocollagen molecule, or oligomeric genipin bridges between tropocollagens, or collagen microfibrils in the pericardium (Sung et al. 2003). Multipoint covalent crosslinking probably hinders collagen digestion due to the inability of the collagenase to penetrate inside the 

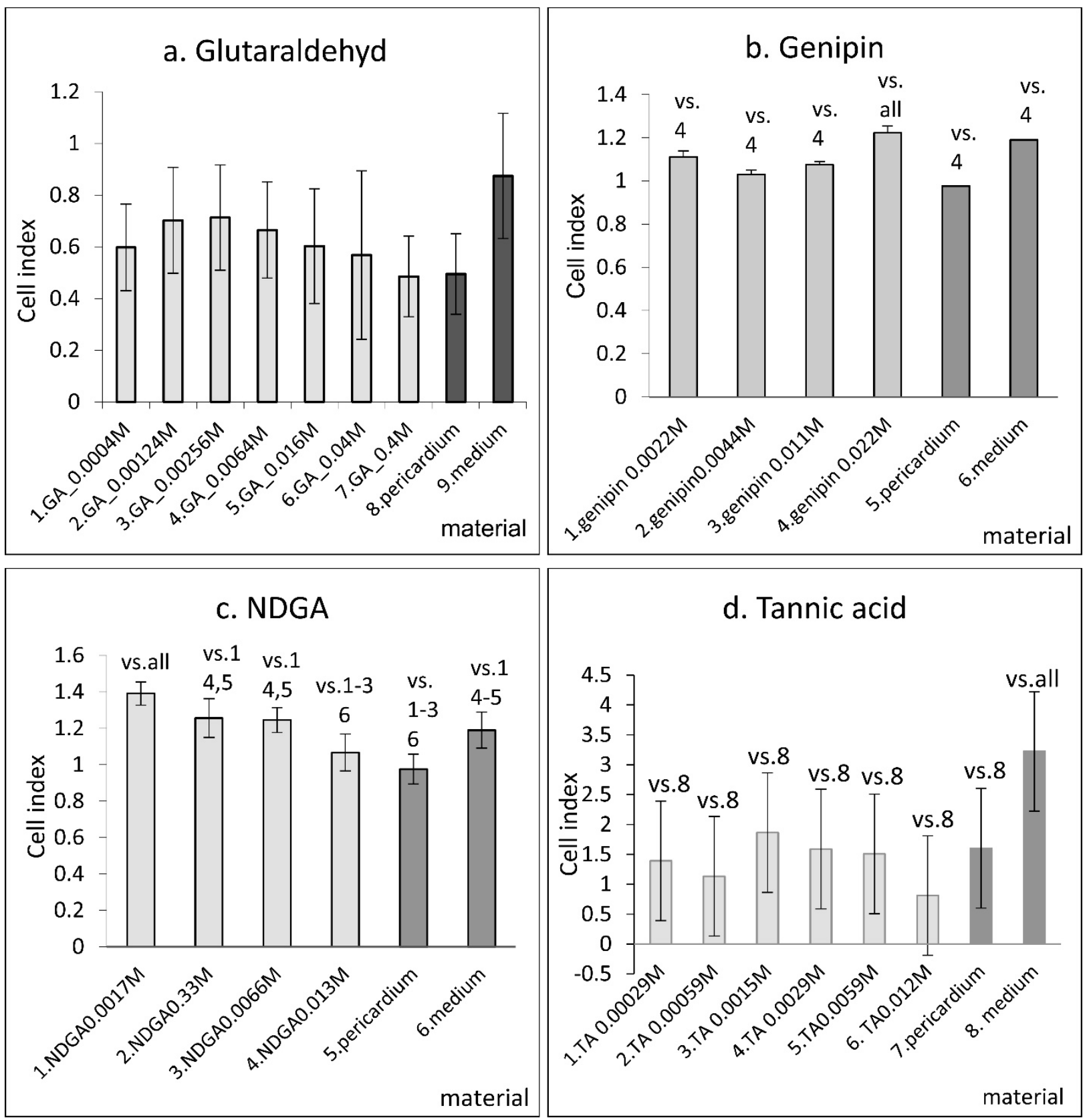

Fig. 6. Cell index of VIC cells on day 5 after cultivation in "elution medium" obtained by a 3-day elution of native human pericardium (pericardium) and pericardium cross-linked with (a) glutaraldehyde at concentrations of $0.0004,0.001,0.00256,0.0064,0.016,0.04$, and $0.4 \mathrm{M}$, with (b) genipin $0.0022,0.0044,0.0011$ and $0.022 \mathrm{M}$, and NDGA $0.0017,0.0033,0.0066$, and $0.013 \mathrm{M}$, and with (c) tannic acid $0.00029,0.00059,0.0015,0.0029,0.0059$, and $0.012 \mathrm{M}$. The data are presented as mean \pm S.D.; $\mathrm{p} \leq 0.05$ is considered significant in comparison with the sample of the same number as depicted above the bars. Evaluated from 3-7 samples of each group, statistical analysis ANOVA, Student-Newman-Keuls method. The elution medium was obtained after incubation of pericardium samples is DMEM supplemented with gentamicin for 3 days, into which $10 \%$ of FBS was added before cell seeding.

collagen fibers and fibrils, and by the inability to unwind triple-helical tropocollagen regions, or because of changes in the collagen structure at the cleavable sites.

Unlike GA and genipin, NDGA and TA do not crosslink collagen via forming covalent bonds with amino groups. NDGA fixes pericardium by the formation of a bisquinone polymer network, in which the collagen fibrils are embedded (Koob and Hernandez 2002, Koob and Hernandez 2003). Collagen can be digested when collagenase penetrates to the fibrils. The crosslinking of collagen fibrils with TA at physiological $\mathrm{pH}$ is mediated mainly by non-covalent hydrogen bonding with multiple TA phenolic hydroxyl groups, and by hydrophobic interactions with TA aromatic rings (Ma et al. 2014). The time lag and the subsequent facilitation of collagenase digestion shown in Figure 5 may be due to loosening of 
the densely-packed collagen fibrils after non-covalently bound TA has been partially released from the pericardium.

The low viability of VICs seeded in eluates from GA crosslinked pericardium (Fig. 5a) corresponded with general GA toxicity and the cytotoxicity of GA grafts (Gough et al. 2002). On the other hand, some cytotoxicity of genipin, which was found to be approx. 10,000 times lower than that of glutaraldehyde (Sung et al. 1999), decreased the positive effect of eluates from genipin crosslinked pericardium on the VICs viability. A weak cytotoxicity of NDGA (Koob et al. 2001) was probably responsible for decreasing VICs viability with increasing NDGA concentration used for the fixation of pericardium (Fig. 5c).

Collagenase digestion of native human pericardium and of pericardium treated with glutaraldehyde, genipin, nordihydroguaiaretic acid and tannic acid has been studied in vitro in order to suggest ways in which the susceptibility of pericardium to in vivo degradation could be decreased. The results have indicated that covalent crosslinking of pericardium with
GA or with genipin provided similarly efficient protection against collagenase digestion, while almost no protection was achieved by non-covalent fixation with NDGA or with TA. In addition, the viability of porcine valve interstitial cells was significantly higher when they were cultivated in eluates from genipin-crosslinked pericardium than when they were cultivated in eluates from pericardium fixed by traditional crosslinking with GA.

\section{Conflict of Interest}

There is no conflict of interest.

\section{Acknowledgements}

This study was supported by Czech Health Research Council projects No. 15-29153A and NV18-02-00422, by MEYS (LM2015062 Czech-BioImaging), and by BIOCEV - Biotechnology and Biomedicine Centre of the Academy of Sciences and Charles University project CZ.1.05/1.1.00/02.0109, funded by the European Regional Development Fund.

\section{References}

BADYLAK SF, GILBERT TW: Immune response to biologic scaffold materials. Semin Immunol 20: 109-116, 2008. https://doi.org/10.1016/j.smim.2007.11.003

BUNYARATAVEJ P, WANG HL: Collagen membranes: a review. J Periodontol 72: 215-229, 2001. https://doi.org/10.1902/jop.2001.72.2.215

CHANG Y, TSAI CC, LIANG HC, SUNG HW: In vivo evaluation of cellular and acellular bovine pericardia fixed with a naturally occurring crosslinking agent (genipin). Biomaterials 23: 2447-2457, 2002. https://doi.org/10.1016/S0142-9612(01)00379-9

CHUNG L, DINAKARPANDIAN D, YOSHIDA N, LAUER-FIELDS JL, FIELDS GB, VISSE R, NAGASE H: Collagenase unwinds triple-helical collagen prior to peptide bond hydrolysis. EMBO J 23: 3020-3030, 2004. https://doi.org/10.1038/sj.emboj.7600318

GOUGH JE, SCOTCHFORD CA, DOWNES S: Cytotoxicity of glutaraldehyde crosslinked collagen/poly(vinyl alcohol) films is by the mechanism of apoptosis. J Biomed Mater Res 61: 121-130, 2002. https://doi.org/10.1002/jbm.10145

JONAS RA: Choosing the right biomaterial. In: Comprehensive Surgical Management of Congenital Heart Disease, 2nd ed. CRC Press, Taylor \& Francis Group, Boca Raton, London, New York, 2014, pp 247-248.

KAWASE I, OZAKI S, YAMASHITA H, UCHIDA S, NOZAWA Y, MATSUYAMA T, TAKATOH M, HAGIWARA S: Aortic valve reconstruction with autologous pericardium for dialysis patients. Interact Cardiovasc Thorac Surg 16: 738-742, 2013. https://doi.org/10.1093/icvts/ivt033

KOOB TJ, HERNANDEZ DJ: Material properties of polymerized NDGA-collagen composite fibers: development of biologically based tendon constructs. Biomaterials 23: 203-212, 2002. https://doi.org/10.1016/S01429612(01)00096-5

KOOB JT, HERNANDEZ DJ: Mechanical and thermal properties of novel polymerized NDGA-gelatin hydrogels. Biomaterials 24: 1285-1292, 2003. https://doi.org/10.1016/S0142-9612(02)00465-9 
KOOB TJ, WILLIS TA, HERNANDEZ DJ: Biocompatibility of NDGA-polymerized collagen fibers. I. Evaluation of cytotoxicity with tendon fibroblasts in vitro. J Biomed Mater Res 56: 31-39, 2001. https://doi.org/10.1002/1097-4636(200107)56:1<31::AID-JBM1065>3.0.CO;2-N

LAEMMLI UK: Cleavage of structural proteins during the assembly of the head of bacteriophage T4. Nature 227: 680-685, 1970. https://doi.org/10.1038/227680a0

LAM MT, WU JC: Biomaterial applications in cardiovascular tissue repair and regeneration. Expert Rev Cardiovasc Ther 10: 1039-1049, 2012. https://doi.org/10.1586/erc.12.99

LEE C, LIM HG, LEE CH, KIM YJ: Effects of glutaraldehyde concentration and fixation time on material characteristics and calcification of bovine pericardium: implications for the optimal method of fixation of autologous pericardium used for cardiovascular surgery. Interact Cardiovasc Thorac Surg 24: 402-406, 2017. https://doi.org/10.1093/icvts/ivw356

LISKOVA J, HADRABA D, FILOVA E, KONARIK M, PIRK J, JELEN K, BACAKOVA L: Valve interstitial cell culture: Production of mature type I collagen and precise detection. Microsc Res Tech 80: 936-942, 2017. https://doi.org/10.1002/jemt.22886

MA B, WANG X, WU C, CHANG J: Crosslinking strategies for preparation of extracellular matrix-derived cardiovascular scaffolds. Regen Biomater 1: 81-89, 2014. https://doi.org/10.1093/rb/rbu009

MIGNEAULT I, DARTIGUENAVE C, BERTRAND MJ, WALDRON KC: Glutaraldehyde: behavior in aqueous solution, reaction with proteins, and application to enzyme crosslinking. Biotechniques 37: 790-796, 798-802, 2004. https://doi.org/10.2144/04375RV01

REMI E, KHELIL N, DI CENTA I, ROQUES C, BA M, MEDJAHED-HAMIDI F, CHAUBET F, LETOURNEUR D, LANSAC E, MEDDAHI-PELLE A: Pericardial processing: challenges, outcomes and future prospects. In: Biomaterials Science and Engineering. PIGNATELLO R (ed.), IntechOpen, London, 2011, pp 437-456. https://doi.org/10.5772/24949

SHOULDERS MD, RAINES RT: Collagen structure and stability. Annu Rev Biochem 78: 929-958, 2009. https://doi.org/10.1146/annurev.biochem.77.032207.120833

STRAKA F, SCHORNIK D, MASIN J, FILOVA E, MIREJOVSKY T, BURDIKOVA Z, SVINDRYCH Z, CHLUP H, HORNY L, DANIEL M, MACHAC J, SKIBOVÁ J, PIRK J, BACAKOVA L: A human pericardium biopolymeric scaffold for autologous heart valve tissue engineering: cellular and extracellular matrix structure and biomechanical properties in comparison with a normal aortic heart valve. J Biomater Sci Polym Ed 29: 599-634, 2018. https://doi.org/10.1080/09205063.2018.1429732

SUNG HW, HUANG RN, HUANG LL, TSAI CC: In vitro evaluation of cytotoxicity of a naturally occurring crosslinking reagent for biological tissue fixation. J Biomater Sci Polymer Ed 10: 63-78, 1999. https://doi.org/10.1163/156856299X00289

SUNG HW, CHANG WH, MA CY, LEE MH: Crosslinking of biological tissues using genipin and/or carbodiimide. J Biomed Mater Res A 64: 427-438, 2003. https://doi.org/10.1002/jbm.a.10346

VINCI C, TESSITORE G, CASTIGLIONI L, PRANDI F, SONCINI M, SANTORO R, CONSOLO F, COLAZZO F, MICHELI B, SIRONI L, POLVANI G, PESCE M: Mechanical compliance and immunological compatibility of fixative-free decellularized/cryopreserved human pericardium. PLoS One 8: e64769, 2013. https://doi.org/10.1371/journal.pone.0064769

WELTERS MJ, OEI FB, VAESSEN LM, STEGMANN AP, BOGERS AJ, WEIMAR W: Increased numbers of circulating donor-specific $\mathrm{T}$ helper lymphocytes after human heart valve transplantation. Clin Exp Immunol 124: 353-358, 2001. https://doi.org/10.1046/j.1365-2249.2001.01557.x 